\title{
A escolha da função pública como campo de emprego para jovens adultos*
}

\author{
Teresa Cristina Carreteiro ${ }^{1}$
}

Universidade Federal Fluminense (Niterói, RJ)

\begin{abstract}
Este artigo comporta três eixos: no primeiro, analisamos brevemente o lugar do mundo do trabalho na cena contemporânea. O segundo apresenta algumas conclusões de uma pesquisa relativa a duas gerações, tendo como objetivo comparar as trajetórias de trabalho de pais com a de seus filhos. A terceira parte é consagrada a um eixo principal da pesquisa: a opção pelo serviço público. Sublinhamos a importância dessa opção, que parece corresponder às expectativas atuais de numerosos jovens.
\end{abstract}

Palavras-chave: Função pública, Emprego, Carreira, Trajetória, Reconhecimento, Utilidade social.

L'attrait de la fonction publique pour les jeunes brésiliens: quelles significations?

Cet article comporte trois axes: Dans le premier nous analysons brièvement la place du monde du travail sur la scène contemporaine. Le deuxième fait état de certaines des conclusions d'une recherche portant sur deux générations dont le but était de comparer les trajectoires de travail de parents et de leurs enfants. La troisième partie est consacrée à un axe principal de la recherche: l'option pour le service public. Nous soulignons l'importance de cette option qui semble correspondre aux attentes actuelles de nombreux jeunes.

Mots-clés: Fonction publique, Emploi, Carrière, Trajectoire, Reconnaissance, Utilité sociale.

The meaning of civil service appeal for Brazilian youngsters

This article is built around three axes. The first one helps us analyze briefly the place of work in the contemporary arena. The second axis is built around some conclusions drawn from a research about the comparison of work trajectories of children and their parents through two generations. The third one deals with a central dimension of the research: the choice of civil service as an occupation. We underline the importance of this option which seems to correspond with the present expectations and wishes of numerous young people.

Keywords: Civil service, Employment, Career, Trajectory, Recognition, Social utility.

\section{Trabalho e contexto contemporâneo}

noção de trabalho é complexa (Pagès, 2002). Por um lado, inclui critérios produtivos,
econômicos e financeiros; por outro, integra aspectos existenciais, subjetivos e
socioculturais. Atualmente, essa complexidade tem apresentado novos contornos. A
vulnerabilidade experimentada no trabalho (Antunes, 2000) surge como questão para os
teóricos, que se perguntam se o trabalho ainda ocupa um lugar central (Barel, 1985; Billiard,
1997). Alguns consideram que este ainda seja o fundamento do laço social. Vários elementos
confirmam essa afirmação: o trabalho permite a possibilidade do aprendizado da vida adulta em
sociedade; a construção da identidade; o acesso às normas que estabelecem a
relação/contribuição/retribuição na qual se baseia o laço social (Méda, 2007).
O trabalho é considerado um dos eixos fundamentais da existência, na medida em que
exerce papel essencial nos processos de inserção e integração. Sob vários aspectos, ele
representa para os indivíduos uma fonte de conquista da autonomia financeira, da consideração

* Publicado originalmente em: Nouvelle Revue de Psychosociologie, 15 (1), 145-162, 2013. DOI: 10.3917/nrp.015.0145

1 Professora do programa de Pos-graduação em Psicologia UFF e pesquisadora do CNPq. 
e do respeito (Sennett, 2004; Castel, 1995; Castel \& Haroche, 2001). Tem, portanto, uma dimensão de integração e de centralidade na vida, apesar do contexto de fragilidade que o abarca atualmente. Participa da inserção dos indivíduos em posições mais ou menos valorizadas, dependendo do grau de reconhecimento social das funções exercidas, e dos capitais sociais, econômicos e financeiros associados a elas. Portanto, o trabalho diz respeito a uma atividade econômica e, ao mesmo tempo, é um elemento central da construção subjetiva e da vida humana (Neves, Seligmann-Silva \& Athayde, 2004; De Gaulejac, 2004; Carreteiro \& Barros, 2011).

Notemos que o trabalho mobiliza diversas dimensões da vida, como o fazer, o ter ou o ser. Praticamente nada lhe escapa (De Gaulejac, 2004). Ele atende às demandas do psiquismo e do social, o que nos faz adotar uma perspectiva clínica para pensá-lo (Lhuilier, 2006). Suas práticas produzem sentido, tanto no que concerne à própria atividade do trabalhador (Clot, 2011) quanto no que diz respeito à construção do sujeito ao longo de sua vida (Amado \& Enriquez, 2011).

A organização do trabalho é impossível de se realizar sem uma constante referência ao outro. Isso nos remete a Hegel (1969), que insistiu na "luta pelo reconhecimento", e a Freud (1981), que demonstrou que "o outro intervém regularmente (na vida psíquica) enquanto modelo, objeto, apoio e adversário". Hegel evidencia o desejo de cada indivíduo de ser reconhecido pelos outros como sujeito, ou seja, como pessoa autônoma, sentindo, desse modo, estima por si próprio. Se o outro (indivíduo, sociedade, Estado) o deprecia, humilha ou rejeita, ele tende a apresentar queda ou eliminação da autoestima, o que pode levar, em casos extremos, à autodestruição.

Assim, os sujeitos humanos tentam, em suas relações afetivas, em seu trabalho, em seu respeito pelas regras sociais, se mostrar mais dignos de serem estimados e reconhecidos pelos outros em todas as suas dimensões. Axel Honneth (2010) estabelece um diálogo entre a obra de Hegel e a de G. H. Mead (1963). Seguindo Mead, destaca que cada homem constrói seu "eu" a partir do olhar, da voz e das posturas dos outros. Dessa forma, o homem adota a perspectiva do outro e a transforma em sua própria atitude. Honneth afirma que tanto Hegel quanto Mead destacam a necessidade que todo indivíduo tem de ser reconhecido como sujeito singular, digno de ser considerado como um verdadeiro cidadão.

Ter um trabalho constitui um dos símbolos da contribuição do indivíduo para a sociedade em que vive. Sem trabalho ou com um trabalho precário, não sendo reconhecido como digno de estima, o próprio indivíduo se qualifica como "cidadão diminuído" (Carreteiro, 1993), com pouca estima em relação a si mesmo, o que gera sofrimento. Além disso, ele se vê excluído dos grandes projetos da sociedade, sente-se responsável por seu fracasso e sofre enorme insegurança com relação ao futuro (Sennett, 1999). A partir dessa constatação, podemos inferir que a precariedade e a instabilidade presentes no mercado de trabalho são causas de sofrimento. O sujeito se vê na figura de um "inútil social" (Carreteiro, 1999), na medida em que a ausência de reconhecimento não pode alimentá-lo narcisicamente.

As grandes mudanças advindas neste último quarto de século (desemprego, crescimento do trabalho informal, instabilidade do emprego) aceleraram a instauração de uma responsabilização individual nos trabalhadores. Muitas vezes as pessoas não entendem a lógica da situação na qual se encontram. Elas não atribuem a origem de seus problemas (particularmente do desemprego) ao mercado de trabalho, mas sim a si mesmas. Esta é uma das consequências da organização neoliberal do trabalho: as exigências que as empresas ou outros mercados têm com relação às pessoas não param de aumentar, dando-lhes, assim, a sensação de nunca estarem à altura delas. 


\section{A análise do trabalho de duas gerações}

Após ter destacado as aceleradas mudanças no campo do trabalho com relação aos próprios trabalhadores, debruçamo-nos sobre as diferenças nas formas de socialização, a partir da história de vida laboral de duas gerações (uma de 50-60 anos e outra de 20-30 anos), oriundas de categorias sociais diversas. Interrogamos essas pessoas acerca das representações que tinham do trabalho, os valores que associavam a ele e o que pretendiam transmitir às próximas gerações. Tais questionamentos foram objeto de uma pesquisa qualitativa que realizamos no Rio de Janeiro. Na época, estávamos interessados na exploração das diferenças e semelhanças existentes entre pais e filhos a respeito da concepção de trabalho. Entrevistamos membros das duas gerações. ${ }^{2}$

A análise da pesquisa demonstrou que os capitais morais (honestidade, responsabilidade, respeito, fidelidade e compromisso), assim como o desejo de fazer um trabalho bem feito e de chegar à realização pessoal, são elementos centrais para as duas gerações. No entanto, os contextos em que elas vivem são muito diferentes.

Quando colocamos em perspectiva a trajetória profissional dos pais e dos filhos, vemos claramente o impacto das transformações do mundo do trabalho sobre os dois segmentos estudados. A geração de 50-60 anos está vivendo grandes transformações no campo das novas tecnologias, do desenvolvimento do mundo virtual e das novas formas de gestão do trabalho. Ela tentou se adaptar a essas transformações no decurso de sua vida de trabalho. Muitas pessoas o fizeram a duras penas, outras encontraram menos obstáculos.

Nossa análise, nesta parte do texto, se baseia no resultado de estudos realizados sobre a trajetória profissional de trabalhadores que exercem alguma atividade de nível técnico. O perfil destes é bastante variado.

Em primeiro lugar, apresentaremos os entrevistados que exercem funções técnicas, mas que aprenderam a trabalhar enquanto exerciam o ofício ou fazendo cursos oferecidos pela empresa. Depois, falaremos daqueles que fizeram um curso universitário, mas que só conseguiram um emprego de nível técnico.

\section{Primeira geração}

1. Os técnicos entrevistados da primeira geração se dividem em dois grupos:

a) a ausência de formação específica não foi impedimento para alcançar empregos técnicos como aprendiz.

Este subgrupo é composto por homens de categoria social pouco privilegiada e que, no início de suas trajetórias de trabalho, só tinham o nível de escolaridade fundamental, com/sem uma pequena experiência técnica. Naquele tempo, essa questão não os impediu de obter empregos nos quais puderam adquirir, posteriormente, qualificações técnicas. $\mathrm{O}$ aperfeiçoamento específico foi sendo adquirido ao longo de suas trajetórias, com a experiência do próprio trabalho. Eles acabaram se tornando, por exemplo, eletricistas ou técnicos em gás em empresas privadas ou públicas.

\footnotetext{
2 Trata-se de uma pesquisa qualitativa. Estimamos que casos analisados em profundidade fornecem elementos mais interessantes para nosso objeto do que vários casos analisados superficialmente, tal como pensavam S. Freud e M. Mauss. As entrevistas foram feitas a partir de um roteiro, em que procuramos seguir as etapas dos percursos de trabalho de cada entrevistado. Essas entrevistas aconteceram em uma atmosfera de confiança. No âmbito da pesquisa, usamos a renda familiar na designação da ABEP (Associação Brasileira de Estudos Populacionais), que estabelece sete classes. Nossos entrevistados pertenciam à famílias cuja renda os colocava na categoria A2 (renda familiar mensal de $\mathrm{R} \$ 6.210,00$ a $\mathrm{R} \$ 10.190,00$ ) e na categoria $\mathrm{D}$ (renda familiar mensal de $\mathrm{R} \$ 479,00$ a $\mathrm{R} \$$ $1.035,00)$.
} 
Essa geração teve a empresa como principal "campo de formação". Ocupar um emprego e se formar eram duas coisas feitas simultaneamente. Eles relatam que a condição de contratação, na época, era simplesmente o nível de escolaridade básico: o diploma primário.

b) A qualificação adquirida em cursos específicos é determinante para a contratação para um cargo técnico.

Este subgrupo é composto de pessoas que tiveram a formação necessária para serem recrutadas pelas empresas privadas ou públicas que demandavam qualificações e competências precisas. Ao longo do exercício dos ofícios, essas pessoas puderam desenvolver as qualidades práticas ligadas a um aprendizado preciso, além de aumentar seus conhecimentos com cursos oferecidos pelas empresas em que trabalhavam.

Os dois grupos fizeram carreiras nas empresas, adquirindo posições econômicas e sociais bem mais importantes do que as de suas famílias de origem.

A pesquisa também permitiu distinguir dois grupos entre as categorias sociais economicamente favorecidas, e que fizeram curso superior.

2. Os entrevistados da primeira geração que cursaram ensino superior:

a) Os profissionais que entraram no mundo do trabalho já tendo terminado uma graduação compativel com seus empregos.

Essas pessoas continuaram a se aperfeiçoar durante sua trajetória profissional. Elas adquiriram outros diplomas universitários, inclusive de pós-graduação.

b) Os profissionais que passaram em concursos para cargos técnicos em empresas públicas ou de economia mista.

Ao longo de sua vida profissional, eles fizeram cursos universitários, mas continuaram exercendo funções técnicas. A atual competitividade no campo do trabalho os motivou a fazer cursos superiores para se sentirem mais valorizados.

A primeira geração tinha certo grau de segurança inerente ao trabalho formal, que garantia a perenidade do emprego (mesmo em empresas privadas) e o sentimento de estabilidade. Os membros dessa geração tinham condições de realizar uma poupança, o que lhes permitia fazer projetos de médio e longo prazo. O contexto no qual seus filhos nasceram e cresceram já se mostra bem diferente.

Atualmente, os profissionais são obrigados a adquirir novas competências, a se requalificar de maneira constante para poder atender aos novos requisitos exigidos pelo mercado de trabalho. A primeira geração entrava nesse mercado formal e contava com certa segurança e estabilidade; no entanto, paulatinamente, uma série de transformações e exigências começou a se inserir no cotidiano laboral, favorecendo o aumento da instabilidade. Assim, durante suas vidas profissionais, essas pessoas viveram experiências variadas. No início, elas podiam se realizar no emprego, aperfeiçoar-se, criar laços e colocar em prática seu valor de compromisso e de fidelidade. Atualmente, prevalecem novas tecnologias e formas de gerenciamento e de administração, características do mundo hipermoderno que exacerbam valores de excelência e de rentabilidade. Tais características são completamente opostas às que lhes eram requeridas no início de sua trajetória, e têm como consequência uma reorganização de suas estratégias e de seus suportes, para que tenham condições de atender a tais exigências.

Nos dias atuais, outros processos estão ocorrendo para permitir a inserção no mercado. Sennett (1999) destaca que o sentimento de insegurança que está invadindo a sociedade, resultado do "novo capitalismo", não oferece mais as condições necessárias a um planejamento de longo prazo. O mercado e as novas relações de trabalho impõem aos indivíduos um vago conjunto de obrigações, compromissos e rápidas tomadas de decisão. Esse conjunto é 
característico da prevalência do curto prazo, e tem importantes implicações na maneira de encarar os novos processos de trabalho.

\section{Segunda geração}

Desde o início, a segunda geração esteve em contato com as novas tecnologias às quais seus pais tiveram de se adaptar durante seus percursos profissionais. Junto com esses novos valores, foram impostas outras condições, tais como trabalhar em muitas frentes e ter a obrigação de dar conta do conjunto de urgências e exigências que recaem a cada dia sobre o trabalhador. Esta geração vive a instabilidade do emprego e se sente impelida a adquirir novas competências para poder entrar, permanecer ou evoluir no trabalho. Tem o sentimento de estar sempre aquém do que lhes é demandado. Podemos aproximar esse sentimento daquilo que Alain Ehrenberg (1998) chamou de "insuficiência do indivíduo contemporâneo", que se vê obrigado a incorporar a exigência social e a superar-se continuamente.

Uma das categorias da segunda geração inclui os jovens que fizeram curso superior enquanto exerciam uma função técnica. Ao terminarem seu curso, não encontraram empregos compatíveis com sua formação. Muitos deles, depois de formados e de um período de desemprego, adotaram a estratégia de não mencionar em seus currículos o fato de terem curso superior.

Independentemente da escolaridade ou do trabalho exercido, atualmente as duas gerações estão sentindo a pressão da competição. Esse aspecto do trabalho é citado tanto pelos que são contratados por empresas privadas quanto por quem exerce algum cargo público. Para os trabalhadores da iniciativa privada, o risco de desemprego é maior. E aumenta ainda mais no caso da geração mais jovem, que entrou para o mercado de maneira diferente da de seus pais.

Ao analisarmos os dados colhidos junto à categoria mais jovem (20-30 anos) com curso superior, identificamos um grande desejo de obter um cargo público. Suas famílias não poupam esforços diante das perspectivas de acesso ao emprego público. Há famílias que têm uma inscrição profissional nesse setor e, para seus jovens, há, de um lado, uma herança familiar, e, de outro, a presença de um contexto atualmente difícil do mercado de trabalho, cuja instabilidade tem um peso determinante em suas motivações.

A importância dada ao emprego público nos levou a redigir vários estudos de caso. No próximo tópico deste artigo, apresentaremos um deles. Analisaremos a trajetória profissional de dois membros da mesma família que trabalham no setor público. Anteriormente, no entanto, devemos dar indicações a respeito dos concursos públicos no Brasil.

\section{O investimento dos profissionais no serviço público e as oportunidades nesse setor}

O desejo de entrar no serviço público aumentou ao longo dos anos, como demonstra a estatística do IBGE: 43\% dos brasileiros da classe média têm essa ambição. Há cada vez mais pessoas graduadas saindo das universidades e se matriculando em cursos preparatórios para concursos.

Nesse contexto, a nossa hipótese é a de que o aumento do número de candidatos se deva a três fatores: a atual instabilidade do mercado de trabalho, o aumento do número de vagas oferecidas pelo setor público e, por fim, a busca do reconhecimento social que o trabalho oferece. 
O funcionalismo público brasileiro passou por inúmeras transformações. Nos anos 1930-1945, foram criados inúmeros cargos nos ministérios. Isso levou a uma grande expansão da administração pública, onde os funcionários puderam, graças a leis especiais, obter novos direitos e prerrogativas. Esse período corresponde ao governo Vargas, que tinha como objetivo central a implantação de uma legislação social trabalhista. Nessa época houve também a criação de um departamento de administração pública no Brasil (1938) e um estatuto administrativo dos funcionários públicos civis da União, a partir de um decreto-lei (1939). O estatuto atual data de 1990. No entanto, mudanças na lei estão atualmente em curso.

A constituição de 1988, redigida após o período militar, representou um marco importante, pois passou a exigir concurso para a ocupação de cargo público.

Já na década de 1990, sob o governo Collor, o panorama se inverteu. Com a reforma do Estado, tem-se como resultado a aposentadoria de 45 mil funcionários. Esse momento ficou conhecido como o da redução e do "desmonte" da máquina administrativa pública. Naquela ocasião, a representação do serviço público era negativa, contribuindo para o processo de enfraquecimento da identidade e da autoestima dos "servidores públicos".

Nos governos seguintes, o setor público passou por uma série de mutações que levaram a uma diminuição significativa do número de servidores. Estima-se que entre o início da reforma da Previdência Social e o fim de 2002, ao término do segundo mandato de Fernando Henrique Cardoso, o serviço público federal tenha perdido 233.820 servidores. Por outro lado, na mesma época, 51.613 pessoas entraram para a função pública. Houve, assim, um déficit de 182.207 servidores.

No governo Lula, a partir de 2003, o serviço público retomou seu vigor. O número de concursos aumentou. Nos anos de 2003 e 2004, 28.342 novos servidores concursados tomaram posse. Essa nova tendência de aumento pode ser compreendida quando são levadas em consideração as quantidades de vagas oferecidas mediante aprovação em concurso público: 59.507 vagas entre janeiro de 2003 e agosto de 2005.

O quadro atual tende à diminuição dessa oferta. No inicio do governo Dilma Roussef, os concursos federais ficaram suspensos durante um ano. Uma das medidas decretadas pela nova presidência, no início do mandato (2011), foi o corte de 50 bilhões no orçamento federal, o equivalente a $1,2 \%$ do produto interno bruto. Essa decisão teve várias repercussões: entre elas, a suspensão da chamada dos aprovados em concurso e a rescisão da maioria dos novos concursos. No ano de 2011, só foram oferecidas 14.600 vagas.

A grande quantidade de cargos públicos oferecidos nos últimos anos fez com que a procura por essas vagas aumentasse sobremaneira e tornou as seleções muito exigentes, contribuindo para uma grande concorrência entre os candidatos. $O$ fato de ter muitas capacidades, diversos diplomas e uma sólida preparação à custa de muito estudo está entre as qualidades exigidas dos "concorrentes". Neste contexto, pode-se identificar um consumo não só de mercadorias: há também um "consumo" intelectual, de capacidades, de certificados de conhecimento e, em grande quantidade, de cursos preparatórios.

\section{Trajetória de trabalho de uma família no serviço público}

Vamos nos referir à trajetória profissional de dois membros de uma mesma família, pai e filha. Analisaremos suas respectivas concepções do trabalho e as diferenças de contexto quando da entrada destas duas pessoas na carreira. Trata-se de uma família de classe média que construiu seus projetos profissionais sob a óptica do funcionalismo público. 
O pai, Leandro, 55 anos, tem nível superior (doutorado), sendo professor universitário em instituição pública. A mãe não trabalha, cuidando exclusivamente das atividades domésticas. Já a filha, Luana, 25 anos, mora com seus pais, é engenheira e tem um cargo público de nível técnico. A família sempre viveu em uma área rural dedicada ao trabalho e, desde muito jovem, o pai, Leandro, teve como projeto uma carreira pública. Durante a entrevista, ele declarou que seus pais eram muito atentos aos estudos dos filhos, queriam que tivessem uma escolaridade sólida (2012).

O pai de Leandro exercia uma função técnica em uma universidade pública rural. Isso os levou a morar também naquela localidade. Leandro viveu e foi cercado pelo ambiente público, não apenas devido ao emprego do pai, mas também à própria vizinhança. Foi nesse contexto que construiu seu projeto profissional. "Desde a idade de 5 ou 6 anos, pela influência de meus pais e do lugar onde moravam (o campus da universidade), já me interessei por minha área profissional". Seus pais contribuíram para a realização desse projeto, ao incentivá-lo a estudar, a despeito da difícil condição financeira. "Reconheço o esforço de meus pais, que me colocaram, assim como meus irmãos e irmãs, em boas escolas privadas". Ele se formou em engenharia agrônoma em universidade pública. Quando terminou, quis fazer concurso para o ensino superior. Ele acrescenta: "Planejei minha vida de trabalho para entrar na universidade como professor". Ele conseguiu realizar seu projeto sem muitas dificuldades, integrando a universidade aos 22 anos, mediante seleção pública. Entrou como professor auxiliar, ainda não era funcionário público.

Naquela época, durante o governo militar, começaram a faltar muitos professores universitários, e muitas pessoas foram selecionadas para exercer temporariamente o cargo de professor substituto. Muitos deles continuaram seu trabalho durante mais de dez anos, construindo laços muito fortes, ainda que precários, com a universidade. Essa situação originou, nos anos 1980, um grande movimento acadêmico de reivindicações e greves por parte dos professores auxiliares que lecionavam nas universidades federais. Graças a essas circunstâncias, Leandro tornou-se funcionário público e professor. A partir de então, sua carreira deslanchou: fez mestrado e, em seguida, doutorado. Seu status e sua atividade como professor lhe deram a oportunidade de aumentar seus conhecimentos e sua experiência, bem como de obter períodos sabáticos para adquirir qualificações acadêmicas.

A legislação das universidades federais prevê que o professor, obtendo autorização do departamento ao qual pertence, pode aprofundar sua qualificação durante um período sabático. Essa disposição legal ainda existe, mas, atualmente, os professores, na maioria dos casos, já ingressam na universidade com o diploma de doutorado. $\mathrm{Na}$ época em que Leandro integrou o serviço público, a universidade carecia dessas especializações, havendo, portanto, fortes incentivos legais para que os professores pudessem se qualificar.

A entrada de Leandro no quadro de docentes, como auxiliar de ensino, aconteceu no final dos anos 1970. O Brasil daquela época estava passando pelo que o governo militar chamava de o "milagre brasileiro", um modo de crescimento imposto pela ditadura através de grandes endividamentos econômicos. A conjuntura nacional e internacional era favorável ao emprego, e o discurso de Leandro era claro: ele não tinha a menor preocupação com isso, já que ele obteve uma boa qualificação de engenheiro em uma universidade pública.

A preferência pelo magistério aconteceu em um momento social propício à sua realização, intimamente ligada à participação em um projeto de sociedade. Não percebemos, em nenhum momento da narrativa de Leandro, uma quebra entre as perspectivas individual e social. Esses dois planos se apresentam sempre conectados.

O desejo de contribuir para mudanças sociais, naquela época, dizia respeito à realização de valores referentes à imagem do "sujeito revolucionário" (Gauchet, 2003), aquele que se sente compelido a promover profundas mutações sociais. $O$ aspecto do serviço público prevalecia sobre o da satisfação individual, sendo a atividade de docência o que possibilitava a 
realização de tal projeto. Isso pode ser observado, por exemplo, na maneira pela qual os conhecimentos eram transmitidos aos alunos. "Ter consciência de que eles (os alunos) não receberão somente uma formação tecnológica de nível superior. Eles são, fundamentalmente, líderes de opinião, pessoas que pensam, que não estão ali para simplesmente aprender receitas. São profissionais reflexivos, que formulam ideias, que aprovam ou criticam. Devem ter uma consciência afiada dos problemas de que falam". Percebemos nessas frases a reivindicação por um pensamento e uma ação engajados.

Leandro crê que o emprego público pode oferecer "segurança no trabalho", "estabilidade", garantia de realização de um trabalho mais satisfatório, em comparação com o dos profissionais da iniciativa privada, que se encontram preocupados com a possibilidade do desemprego. Acresce-se a isso a questão da previdência: um dos direitos adquiridos na organização pública permite que os funcionários recebam a integralidade de seus salários quando se aposentarem.

Com relação ao valor do trabalho, Leandro acredita que este é essencial para a vida humana, afirmando:

[...] as pessoas não produtivas perdem grande parte do prazer de se sentirem vivas. Trabalhar é uma ação e dá às pessoas o sentimento de estar vivo, especialmente às que trabalham com satisfação e prazer. Acho que a maioria das pessoas trabalha sem se focar no dinheiro recebido, ainda que saibamos que elas sempre esperam que sua remuneração aumente. $O$ trabalho realizado é uma satisfação e um ideal para as pessoas. Elas também se realizam emocionalmente.

Os valores relacionados ao trabalho - e citados desde o início da entrevista - são, aqui, "prazer, satisfação, realização dos ideais". Em outros momentos, Leandro fala da importância da independência financeira. Reconhece também que tais valores não são os mesmos que interessam à maior parte das pessoas atualmente, já que, para elas, a necessidade é que está na origem de sua atividade.

Em determinados momentos da entrevista, Leandro inclui na categoria de trabalho as atividades não remuneradas, ressignificando esse grupo de modo que ele represente todos os ofícios que tenham um valor para a sociedade. Para Leandro, uma grande quantidade de ações pode ser incluída na esfera do trabalho. ${ }^{3}$

Seus pais lhe transmitiram valores como honestidade, sinceridade, respeito às pessoas idosas e disciplina na vida e no trabalho. Esses são valores que ele aprecia e que transmitiu a seus filhos.

Sua carreira tem um plano claro de progressão. Ele sabe da importância de se ter acesso ao nível superior e de se obter uma melhoria salarial. A produtividade é o elemento principal da avaliação. As atividades de docência são as "de ensino, pesquisa e extensão". Cita as exigências da universidade atual, particularmente a grande pressão exercida para publicar em revistas "de excelência". Essa produção é uma das "obrigações necessárias para subir na carreira de professor, assim como as pesquisas e as participações em congressos". Por isso, apesar de se realizar com seu trabalho, ele não nega a grande pressão que existe atualmente: "ou estamos dentro ou somos rejeitados".

Luana, filha de Leandro, também exerce função na mesma instituição que o pai. Recentemente, ela passou em um concurso de nível médio, para a vaga de técnica administrativa. Como é engenheira, ocupa um cargo inferior ao que poderia pretender em função de sua formação. Apesar disso, Luana está muito satisfeita com sua aprovação no

3 No Brasil não se faz, como na França, diferença entre emprego e trabalho. Quando alguém ocupa um emprego público, ainda que pouco valorizado socialmente, na maioria das vezes deseja dar a ele um toque pessoal e prestar serviço à sociedade. Assim, qualquer emprego deveria permitir, idealmente, a realização de certo grau de criatividade. O trabalho ainda é um valor central no Brasil, pois todas as pessoas que têm um emprego têm sua "carteira de trabalho". As pessoas com carteira de trabalho assinada sentem-se oficialmente destacadas (particularmente aos olhos da polícia) dos delinquentes. 
concurso. $\mathrm{O}$ interesse pelo emprego foi motivado pela estabilidade oferecida pelo serviço público. Ela está há pouco tempo no cargo, portanto em período de estágio probatório. Contudo, não quer se manter nessa função por muito tempo. Ela pretende realizar outros concursos públicos, compatíveis com sua qualificação. Considera que, apesar das vantagens de seu trabalho atual, este representa um momento de transição em seu percurso: "é lógico que eu não vou ficar nesta função para o resto da vida". Ela não fez o concurso pensando no cargo em si, mas em ser funcionária pública.

Sobre o emprego atual, Luana gosta de exercê-lo e tem bastante interesse por ele, porém reafirma que não é o que realmente quer. Seus valores abarcam a realização através do trabalho, o trabalho bem feito e o serviço à coletividade. Pretende fazer mestrado, mas, como está em estágio probatório, ainda não pode obter a dispensa necessária. Por isso, resolveu fazer uma pós-graduação lato sensu, já que os horários das aulas não se confundem com os de sua jornada de trabalho. Sua conduta profissional está focada na construção de uma melhor qualificação. Ao concluir o curso, poderá obter um aumento de salário, conforme previsão do plano de carreira para sua função. Ela visa a uma trajetória de qualificações, aumentando seus conhecimentos e ao mesmo tempo construindo um currículo que lhe propicie melhorias profissionais.

Para Luana, trabalhar significa poder contribuir para melhorar seu espaço de atuação, procurando maneiras mais garantidas de socialização e de integração, em função das vantagens oferecidas pelo setor no qual exerce suas atividades. Ela insiste nos valores de independência financeira, de autonomia e de realização pessoal através do trabalho. Atualmente, considera-se satisfeita, pois, desde que começou no emprego de nível técnico, vem tendo mais autonomia.

Luana considera que ter estudado em colégios privados foi primordial para ingressar em uma universidade pública. Valoriza a importância de um estudo de qualidade. Pretende conseguir, no futuro, quando tiver filhos, transmitir a eles o desejo de fazer o que desejarem e a consciência da importância do estudo. Esse aspecto pode ser visto como um legado familiar, pois desde seus avós tais transmissões estão presentes. Elas refletem também ideias muito difundidas socialmente (Magalhães Seixas \& Féres-Carneiro, 2005).

Se fizermos comparações entre os trajetos laborais de Leandro e Luana, perceberemos que seus trabalhos se inserem em uma tradição familiar na qual é forte o laço com o serviço público. Para ambos, o trabalho é o organizador da vida e dos aspectos habitacionais - vivem em meio rural, junto à universidade pública. Como vimos, Leandro já vivia naquela localidade havia vários anos, tendo sido seu pai funcionário da mesma instituição. ${ }^{4}$ Notemos que a herança da valorização do emprego público não pode ser analisada fora das variantes do contexto.

A fragilidade atual dos laços de trabalho nas empresas privadas fez do serviço público, de vinte anos para cá, um atrativo para a grande maioria dos jovens. Isso vem se intensificando nestes últimos anos, com a grande quantidade de vagas oferecidas pelos concursos, aos quais os jovens aderem em grande escala. Ponderamos, então, que a escolha de Luana pelo funcionalismo público ocorreu por dois motivos: a tradição familiar, segundo a qual o servidor tem um papel essencial na construção da sociedade, e a forte instabilidade do atual contexto do mercado de trabalho.

Tanto o pai quanto a filha consideram o trabalho uma forma de realização pessoal, que ao mesmo tempo propicia algo para a sociedade. Apesar desse consenso, os dois apresentam formas distintas em suas escolhas pelo emprego público.

Luana, como inúmeros jovens adultos de sua geração, socializa-se levando em conta a obrigação de atualização profissional através de cursos e a obtenção de diplomas valorizados

4 No Brasil, à exceção dos camponeses "sem terra" do Nordeste que migram de bom grado para os Estados do Sul em busca de trabalho, na maior parte das vezes os indivíduos permanecem na região ou na cidade em que sua família reside. Leandro e Luana seguem esse padrão. 
para obter melhores empregos. Ela está sempre muito atenta à possibilidade de ser atingida pela instabilidade do mercado, o que a levou a prestar concurso para um cargo público de nível técnico.

Seu pai, em contrapartida, graças ao contexto empregatício favorável de sua época, no começo de sua carreira pôde unir os dois pontos a que aspirava: ser um funcionário público que atua de forma compatível com suas qualificações profissionais e (mais importante) concretizar um desejo que surgira ainda na juventude: ser professor e pesquisador. Ao ingressar na universidade, ele pode construir sua carreira, até se tornar um professor efetivo, passando lentamente por cada etapa.

O percurso profissional de Luana está sendo construído de maneira diferente. A geração em que ela se insere é mais autônoma. Sua trajetória se molda ao que denominamos "gestão da trajetória profissional": cada indivíduo se torna seu próprio gestor, tendo de pensar na melhor maneira para administrar seu percurso profissional. Portanto, ela não se encontra na mesma situação que o pai, ligada ao emprego que ocupa. Ela agora precisa demonstrar a capacidade de tomar iniciativas. Como qualquer jovem dos tempos atuais, Luana paga por seus investimentos e necessita adquirir novas habilidades: "busco ficar sempre atualizada e melhorar minhas competências". Ela leva em conta a competição no mercado, que privilegia a empregabilidade "dos que são diferentes, que não são iguais a todo mundo". Podemos dizer que seu pai teve uma carreira profissional e que ela, por sua vez, tem uma trajetória profissional. ${ }^{5}$

No entanto, as carreiras foram afetadas por várias mudanças ao longo das duas últimas décadas. Leandro reconhece que, no âmbito do trabalho público e privado, as exigências de produtividade aumentaram. Segundo ele, as pessoas devem "se atualizar" continuamente para não se tornarem obsoletas. É o que vai permitir a inserção. Ele considera que, em seu caso, o fato de se manter atualizado lhe dá a possibilidade de participar e de gozar de uma posição ativa.

Vemos que as perspectivas de Leandro e de Luana comportam, ao mesmo tempo, semelhanças e diferenças. A estabilidade, a autonomia e a independência financeira são valores essenciais para Luana. Estes foram os motivadores principais para que ela tentasse (e conseguisse) o emprego atual. Já para o Leandro, essas mesmas condições aparecem como importantes, estão incorporadas em seu trabalho, contudo seu enfoque é no que ele pode devolver para a sociedade. Esse valor é partilhado por sua filha, mas o nível de prioridade que ela lhe confere é outro. Ela vai espreitando as brechas que vão surgindo para adquirir melhores condições no trabalho e em sua trajetória.

Essas duas gerações, ainda que permeadas por valores similares, lhes dão significados diversos. A filha socializa-se em um contexto de instabilidade do emprego, o que não foi o caso do pai. Foi ciente dessa instabilidade que ela ingressou em emprego de nível técnico para, mais tarde, realizar outros concursos compatíveis com sua formação.

\section{Conclusão}

Para concluir, destacamos que a trajetória de Luana é exemplar da posição de outros jovens entrevistados. Muitos integram o serviço público e têm as mesmas perspectivas e os mesmos tipos de projetos que ela. Muitos deles prestam concurso para funções inferiores à suas qualificações.

5 Uma carreira pode ser prevista antecipadamente e acontecer em um só lugar e uma só "empresa”. Já uma trajetória vai sendo gerida de acordo com as circunstâncias, pois cada um deve se tornar, de acordo com a fórmula atual, "o empreendedor de sua própria vida". 
Se fizermos uma comparação entre os jovens que participaram da pesquisa e que não pretendem prestar concursos públicos e os outros jovens, há pontos de convergência entre suas trajetórias e estratégias de busca de emprego. Como vimos, jovens postulantes a cargos da iniciativa privada omitem em seu currículo muitos cursos realizados. Eles acreditam que, em determinadas situações, o excesso de qualificações pode ser contraproducente na busca por certos empregos. Os que são aprovados em concurso público muitas vezes fazem como Luana: prestam concursos de nível técnico, mesmo tempo curso universitário.

Já inseridos no setor público, os jovens prestarão outros concursos com o objetivo de um dia ocupar a função desejada. No setor privado, muitas pessoas exercem funções inferiores a sua qualificação e continuam buscando novas qualificações para conseguir mudar de emprego.

Devemos destacar duas observações:

- Os jovens estão incorporando a ideia de serem os gestores ativos de suas trajetórias profissionais, que se encontra em permanente transformação. Estão ocupando empregos que consideram como transitórios. Os que já se encontram no serviço público prestarão outros concursos. Já os profissionais do setor privado consideram que vão conseguir trocar seu emprego atual por outro que ofereça mais vantagens;

- A preocupação das pessoas com sua trajetória profissional nos leva a pensar que o desejo de ter um trabalho que leve em conta ao mesmo tempo realizações subjetivas e financeiras é o foco de certos indivíduos cuja subjetividade podemos qualificar de "mutante".

No serviço público, esse tipo de subjetividade é a "subjetividade concursante" (Oliveira Santos, 2012). Destaquemos dois aspectos relativos a esse último caso: o foco no mundo do trabalho invade grande parte da existência dos jovens. Além do trabalho exercido, suas horas de folga são dedicadas à preparação para outros concursos. Assim, suas vidas giram em torno do emprego atual, sempre provisório, e do desejo de obter um trabalho mais compatível com suas qualificações. Essas pessoas incorporam um aspecto importante do trabalho contemporâneo: a obrigação de se superar, de concorrer, de ser competitivo. Na perspectiva de trabalho, viver é um desafio contínuo. Se compararmos o percurso de duas gerações, incluindo tanto funcionários públicos quanto profissionais da iniciativa privada, vemos que a primeira geração vê o contexto de trabalho como um polo de formação. Na época dos pais, não havia uma enorme exigência de qualificação. $O$ cenário atual é bem diferente. As empresas exigem que seus funcionários tenham o máximo possível de aptidões para ocupar seu emprego de maneira eficaz. A competição está cada vez mais forte. Cada jovem deve criar condições para se distinguir e seguir formações às vezes ininterruptas para se sentir competitivo e poder encarar as novas exigências do mercado de trabalho.

\section{Referências}

Amado, G. \& Enriquez, E. (2011). Psicodinâmica do trabalho e psicossociologia. In P. F. Bendassolli \& L. A. P. Soboll (Orgs.), Clínicas do trabalho (pp. 99-109). São Paulo: Atlas.

Antunes, R. (2000). Adeus ao trabalho. São Paulo: Cortez.

Aubert, N. \& Pagès, M. (1989). Le stress professionnel. Paris: Klincksieck.

Barel, Y. (1985). La société du vide. Paris: Seuil.

Billiard. I. (1997). Le grand integrateur: crise du travail, crise de sens et crise du lien social. In B. Appay \& A. Thebaud-Mony (Orgs.), Precarisation sociale, travail et santé (pp.182-193). Paris: Iresco.

Carreteiro, T. C. O. C. (1993). Exclusion sociale et construction de l'identité. Paris: L'Harmattan. 
Carreteiro, T. C. O. C. (1999). A doença como projeto: uma contribuição à análise de formas de filiações e desfiliações sociais. In B. B. Sawaia (Org.), As artimanhas da exclusão: análise psicossocial e ética da desigualdade social (pp. 87-96). Petrópolis: Vozes.

Carreteiro, T. C. O. C. (2012). História de vida laboral familiar em duas gerações: trabalho e contextos sociais. In T. Féres-Carneiro (Org.), Casal e família: conjugalidade, parentalidade e psicoterapia (pp. 119-132). São Paulo: Casa do psicólogo.

Carreteiro, T. C. O. C. \& De Barros, V. A. (2011). Clínicas do trabalho: contribuições da psicossociologia no Brasil. In P. F. Bendassolli \& L. A. P. Soboll (Orgs.), Clínicas do trabalho (pp. 208-226). São Paulo: Atlas.

Castel, R. (1995). Les métamorphoses de la question sociale. Paris: Fayard.

Castel, R. \& Haroche, C. (2001). Propriété privée, propriété sociale, propriété de soi, Paris: Arthème Fayard.

Clot, Y. (2011). Clínica do trabalho e da atividade. In P. F. Bendassolli \& L. A. P. Soboll (Orgs.), Clínicas do trabalho (pp. 71-83). São Paulo: Atlas.

De Gaulejac, V. (2004). Le sujet manqué. In N. Aubert (Org.), L'individu hypermoderne (pp. 129-143). Paris: Érès.

Ehrenberg, A. (1998). La fatigue d'être soi. Dépression et société. Paris: Odile Jacob.

Freud, S. (1981). Psychologie des foules et analyse du moi. In Essais de psychanalyse (pp. 123-219). Paris: Payot. (Original publicado em 1921).

Gauchet, M. (2003). La condition historique. Paris: Stock.

Hegel, G. W. F. (1969). La première philosophie de l'esprit. Paris: PUF. (Original publicado em 1805)

Honneth, A. (2010). La lutte pour la reconnaissance. Paris: Éditions du Cerf. (Original publicado em 1992)

Lhuilier, D. (2006). Cliniques du travail. Paris: Toulouse: Érès.

Magalhães Seixas, A. \& Féres-Carneiro, T. (2005). Conquistando a herança: sobre o papel da transmissão psíquica familiar no processo de subjetivação. In T. Féres-Carneiro (Org.), Família e casal: efeitos da contemporaneidade (pp. 24-32). Rio de Janeiro: PUC.

Mead, G. H. (1963). L'esprit, le soi, la société. Paris: PUF. (Original publicado em 1934)

Méda, D. (1995). Le travail: une valeur en voie de disparition. Paris: Aubier.

Méda, D. (2007). Le travail, que sais-je? Paris: PUF.

Neves, M., Seligmann-Silva, E. \& Athayde, M. (2004). Saúde mental e trabalho: um campo de estudo em construção. In A. M. F. Araújo et al. (Orgs.), Cenários do trabalho: subjetividade, movimento e enigma (pp. 19-49). Rio de Janeiro: DP\&A.

Pagès, M. (1986). Trace ou sens. Paris: HG.

Pagès, M. (2002). Complexité. In J. Barus-Michel, E. Enriquez \& A. Levy (Orgs.), Vocabulaire de psychosociologie (pp. 83-93). Toulouse: Érès.

Oliveira Santos, B. (2012). O fenômeno do concurso público: análise do cenário contemporâneo do trabalho. Projeto de Doutorado, Pós-graduação de Psicologia da Universidade Federal Fluminense, Niterói, RJ.

Sennett, R. (1999). A corrosão do caráter: consequências pessoais do trabalho no novo capitalismo. Rio de Janeiro: Record.

\section{Endereço para correspondência \\ teresa.carreteiro@wanadoo.fr}

